\title{
PKA Mediates Constitutive Activation of CFTR in Human Sweat Duct
}

\author{
M. M. Reddy • P. M. Quinton
}

Received: 14 January 2009/Accepted: 23 September 2009/Published online: 29 October 2009

(C) The Author(s) 2009. This article is published with open access at Springerlink.com

\begin{abstract}
The cystic fibrosis transmembrane conductance regulator (CFTR) $\mathrm{Cl}^{-}$channels are constitutively activated in sweat ducts. Since phosphorylation-dependent and independent mechanisms can activate CFTR, we sought to determine the actual mechanism responsible for constitutive activation of these channels in vivo. We show that the constitutively activated CFTR $\mathrm{Cl}^{-}$conductance (gCFTR) in the apical membrane is completely deactivated following $\alpha$-toxin permeabilization of the basolateral membrane. We investigated whether such inhibition of gCFTR following permeabilization is due to the loss of cytoplasmic glutamate or due to dephosphorylation of CFTR by an endogenous phosphatase in the absence of kinase activity (due to the loss of kinase agonist cAMP, cGMP or GTP through $\alpha$-toxin pores). In order to distinguish between these two possibilities, we examined the effect of inhibiting the endogenous phosphatase activity with okadaic acid $\left(10^{-8} \mathrm{M}\right)$ on the permeabilization-induced deactivation of gCFTR. We show that okadaic acid (1) inhibits an endogenous phosphatase responsible for dephosphorylating cAMP but not cGMP or G protein-activated CFTR and (2) prevents deactivation of CFTR following permeabilization of the basolateral membrane. These results indicate that distinctly different phosphatases may be responsible for dephosphorylating different kinase-specific sites on CFTR. We conclude that the phosphorylation by PKA alone
\end{abstract}

M. M. Reddy $(\square) \cdot$ P. M. Quinton

Department of Pediatrics, UCSD School of Medicine,

University of California, San Diego, 9500 Gilman Drive 0830,

La Jolla, CA 92093, USA

e-mail: mmr@ucsd.edu

P. M. Quinton

Division of Biomedical Sciences, University of California,

Riverside, CA 92507, USA appears to be primarily responsible for constitutive activation of gCFTR in vivo.

Keywords CFTR $\cdot \Delta$ F508 CFTR $\cdot$ R117H CFTR .

PKA $\cdot$ PKG $\cdot$ G proteins $\cdot$ Glutamate $\cdot \alpha$-toxin .

Okadaic acid

\section{Introduction}

Generally, epithelial ion channels are thought to be activated by neurohumoral stimuli in response to electrolyte transport demand but to remain inactive in the absence of such stimuli. In contrast, however, the cystic fibrosis transmembrane conductance regulator (CFTR) $\mathrm{Cl}^{-}$channels are constitutively activated in the native human sweat ducts in the complete absence of neurohumoral stimuli (Quinton and Reddy 1994; Reddy and Quinton 1992). The intracellular mediators and mechanism(s) underlying this phenomenon of constitutive activation of gCFTR are unknown.

CFTR is very unique among ion channels with respect to multiple regulatory controls that may involve PKC (Berger et al. 1993; Jia et al. 1997), PKA (Cheng et al. 1991; Dulhanty and Riordan 1994), PKG (French et al. 1995; Picciotto et al. 1992; Vaandrager et al. 1996, 1998), $\mathrm{Ca}^{2+}$ calmodulin-dependent protein kinases (Picciotto et al. 1992), protein tyrosine kinases (Gadsby and Nairn 1999) and different protein phosphatases (Berger et al. 1993; Fischer et al. 1998; Gadsby and Nairn 1999; Luo et al. 1998). Even though these studies implicate several kinases and phosphatases in regulating CFTR, we do not know which of these regulatory processes are tissue-specific or whether different mechanisms control CFTR within most epithelial cells. We have previously shown that the CFTR 
in the apical membrane of native human sweat duct can be activated by phosphorylation-dependent (mediated by cAMP, cGMP and heterotrimeric $G$ protein-dependent kinases) and phosphorylation-independent (mediated by cytoplasmic glutamate and its metabolites) mechanisms (Quinton and Reddy 1991, 1992; Reddy and Quinton 1994, 2001, 2003, 2005a, 2006). The objective of this study was to determine which of these regulatory mechanisms is primarily responsible for constitutive activation of CFTR $\mathrm{Cl}^{-}$channels in vivo.

We used basolaterally $\alpha$-toxin-permeabilized sweat duct as a model system to investigate the endogenous mechanism(s) involved in the constitutive activation of gCFTR. We have previously reported that $\alpha$-toxin permeabilization of the basolateral membrane causes a gradual decrease in transepithelial electrical conductance due to the loss of gCFTR, which in permeabilized ducts could be reactivated either by exogenous stimulation by adding back cAMP, cGMP or GTP- $\gamma-S$ in the presence of ATP or by application of glutamate (or its metabolite $\alpha$-ketoglutarate or glutamine) (Quinton and Reddy 1991, 1992; Reddy and Quinton 1994, 2001, 2003, 2005a, 2006). These observations suggest that the deactivation of constitutively activated gCFTR could be due to the loss of any of these putative intracellular agonists in vivo. That is, inhibition of gCFTR following $\alpha$-toxin permeabilization could be either due to cytosolic loss of cyclic nucleotides that mediate different kinases responsible for phosphorylating CFTR or due to loss of glutamate (or its metabolites), which is known to stimulate CFTR by a mechanism that is independent of phosphorylation. Earlier studies also indicated that while phosphorylation activation of CFTR required physiological concentration of ATP ( $5 \mathrm{mM})$, glutamate activation of gCFTR is independent of ATP (Reddy and Quinton 2003) and that inhibiting ATP production by metabolic poisoning with carbonyl cyanide $m$-chlorophenylhydrazone (CCCP) and 2-deoxyglucose (2DG) caused spontaneous deactivation of the constitutively activated CFTR in the intact, nonpermeabilized sweat duct (Quinton and Reddy 1992). These early data suggested that the constitutive activation of CFTR in this tissue may involve an ATP-dependent phosphorylation process rather than a phosphorylation-independent, glutamate-mediated mechanism. Based on these observations, we sought to test the hypothesis that endogenous phosphorylation of CFTR is responsible for constitutive activation of gCFTR in vivo. We tested the hypothesis by determining the effects of inhibiting endogenous phosphatase activity on the deactivation of gCFTR that follows $\alpha$-toxin permeabilization of the basolateral membrane. The rationale behind this strategy was that if CFTR is dephosphorylated by endogenous phosphatase in the absence of kinase stimulation (due to loss of cAMP, cGMP or GTP through $\alpha$-toxin pores), we should be able to prevent deactivation by inhibiting the okadaic acid-sensitive endogenous phosphatase that prevents dephosphorylation of PKA-activated CFTR (Reddy and Quinton 1996). On the other hand, if constitutive CFTR activation is due to cytoplasmic levels of glutamate (or its precursors), okadaic acid should not prevent CFTR rundown during and after permeabilization with $\alpha$-toxin. We show that inhibiting endogenous phosphatase activity with okadaic acid before permeabilization virtually abolished $\alpha$ toxin-induced deactivation of CFTR so long as ATP was present in the cytoplasmic bath. We conclude that constitutive activation of gCFTR in this tissue results from persistent phosphorylation of CFTR by a kinase whose activity exceeds that of an okadaic acid-sensitive phosphatase, probably protein phosphatase 2A (PP2A), which appears to be responsible for dephosphorylating this channel (Reddy and Quinton 2006).

\section{Methods}

Tissue Acquisition

Sweat glands were obtained from adult male volunteers who gave informed consent. Full-thickness skin biopsies (3 mm diameter) were taken over the scapula and stored in Ringer solution. Individual sweat glands were isolated from the biopsy in cold Ringer solution by dissection with fine-tipped tweezers visualized at $\times 80$ magnification. The isolated glands were transferred to a dissection cuvette with Ringer solution cooled with a peltier block to $4^{\circ} \mathrm{C}$ where the segments of reabsorptive duct ( $>1 \mathrm{~mm}$ in length) were separated from the secretory coil of the sweat gland. The sweat duct was transferred to a perfusion chamber containing Ringer solution at $35 \pm 2{ }^{\circ} \mathrm{C}$.

\section{Selective Permeabilization of the Basolateral Membrane}

The basolateral membrane of the sweat duct was selectively permeabilized with the pore-forming agent $\alpha$-toxin $(1,000$ units/ml) in cytoplasmic Ringer solution containing $140 \mathrm{mM}$ KGlu (potassium gluconate) and $5 \mathrm{mM}$ ATP. $\alpha$-Toxin was applied to the basolateral surface of the microperfused sweat duct for 15-30 min. $\alpha$-Toxin forms pores that pass molecules of 3,500-5,000 mwu (Quinton and Reddy 1992) so that the concentration of intracellular molecules such as cAMP and ATP as well as $\mathrm{pH}_{i}$ can be clamped by their concentration in the extracellular bath solution.

\section{Electrical Measurements}

After cannulating the lumen of the sweat duct with a double lumen cannula made from theta glass $(1.5 \mathrm{~mm}$ 
diameter; Clark Electromedical Instruments, Reading, UK), a constant current pulse of 50-100 nA for a duration of $0.5 \mathrm{~s}$ was injected through one barrel of the cannulating pipette containing $\mathrm{NaCl}$ Ringer solution. The other barrel of the cannulating pipette served as an electrode for measuring transepithelial potential $\left(V_{\mathrm{t}}\right)$ with respect to the contraluminal bath and as a cannula for perfusing the lumen of the duct with selected solutions. $V_{\mathrm{t}}$ was monitored continuously using one channel of a WPI-700 dual electrometer (Sarasota, FL, USA) referenced to the contraluminal bath. Since the sweat duct is a tubular epithelium whose lumen is a conductive core surrounded by an insulating epithelium, we measured the transepithelial specific conductance $\left(G_{\mathrm{t}}\right)$ as described earlier from the amplitude of transepithelial voltage deflections in response to transepithelial constant current pulse using a cable equation (Greger 1981; Helman et al. 1971; Quinton and Reddy 1992; Reddy, Light and Quinton 1999). Our general experimental protocol was to first allow spontaneous deactivation of CFTR and perifuse the cytosol with $\mathrm{K}^{+}$or $\mathrm{Na}^{+}$gluconate while perfusing the lumen with $\mathrm{NaCl}$ Ringer solution. Epithelial $\mathrm{Na}^{+}$channels $(\mathrm{ENaCs})$ were always blocked by amiloride $\left(10^{-5} \mathrm{M}\right)$. The integrity of the tissue was first confirmed by a large increase in CFTR $\mathrm{Cl}^{-}$conductance (gCFTR) following the application of cAMP and ATP as shown (Fig. 1).
CFTR $\mathrm{Cl}^{-}$conductance (gCFTR) in ducts after inhibiting $\mathrm{ENaC}$ conductance with luminal amiloride was calculated using the following formula: $G_{\mathrm{t}}=\mathrm{gCFTR}+\mathrm{gX}$, where $G_{\mathrm{t}}$ is total transepithelial conductance after stimulating gCFTR (with agonists such as cAMP, cGMP, G proteins or glutamate in the cytoplasmic bath) and $\mathrm{gX}$ is a nonspecific shunt conductance measured after blocking gENaC (with luminal amiloride) and gCFTR (by removing CFTR agonists from cytoplasmic bath). The aforementioned formula used to calculate the magnitude of gCFTR is based on the fact that CFTR and $\mathrm{ENaC}$ provide the predominant (probably only) $\mathrm{Cl}^{-}$and $\mathrm{Na}^{+}$conductance pathways in this tissue (Quinton 1986; Reddy and Quinton 1994).

\section{Solutions}

The luminal perfusion Ringer solutions contained (in $\mathrm{mM}$ ) $\mathrm{NaCl}, \mathrm{KCl}$ or $\mathrm{KHCO}_{3}^{-}(150) ; \mathrm{K}^{+}(5) ; \mathrm{PO}_{4}(3.5) ; \mathrm{MgSO}_{4}$ (1.2); and $\mathrm{Ca}^{2+}$ (1) (pH. 7.4). $\mathrm{Cl}^{-}$free luminal Ringer solution was prepared by complete substitution of $\mathrm{Cl}^{-}$with the impermeant anion gluconate. The cytoplasmic/bath solution contained (in $\mathrm{mM}$ ) $\mathrm{K}^{+}$(145), gluconate (140), $\mathrm{PO}_{4}$ (3.5), $\mathrm{MgSO}_{4}$ (1.2) and $260 \mu \mathrm{M} \mathrm{Ca}{ }^{2+}$ buffered with $2.0 \mathrm{mM}$ EGTA (Sigma, St. Louis, MO) to $80 \mathrm{nM}$ free $\mathrm{Ca}^{2+}$ (pH 6.8). $\mathrm{K}^{+}$ATP (0.01-5 mM), cAMP (0.1 mM), cGMP
A

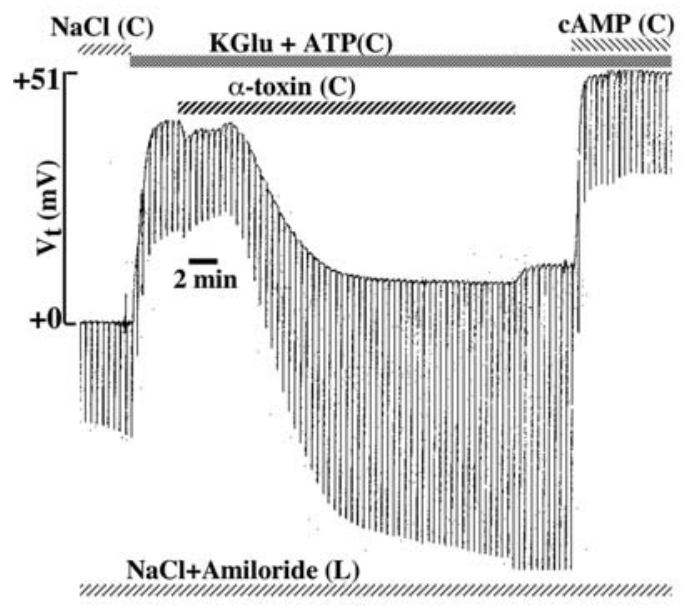

B

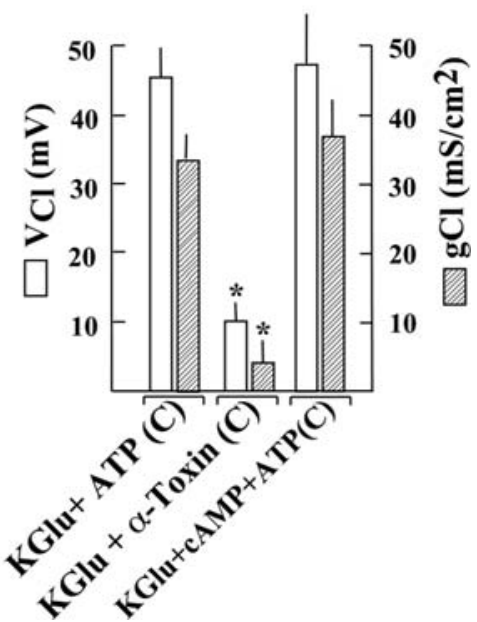

Fig. 1 Effect of $\alpha$-toxin and cAMP on transepithelial electrical properties. a A representative electrical trace showing the effect of permeabilization of basolateral membrane with $\alpha$-toxin. In this experiment, lumen and bath were perfused with $150 \mathrm{mM} \mathrm{NaCl}$ and $140 \mathrm{mM}$ KGlu $+5 \mathrm{mM}$ ATP, respectively. The amiloride-sensitive ENaCs in the apical membrane were blocked by amiloride. Under these conditions, the lumen positive transepithelial potential and conductance predominantly reflect $\mathrm{Cl}^{-}$conductance. Notice that $\alpha$ toxin permeabilization caused progressive loss of transepithelial electrical conductance and lumen positive electrical potential. Hence, the experimental changes in the electrical properties induced by $\alpha$ toxin permeabilization of the basolateral membrane primarily reflect loss of $\mathrm{CFTR}^{-}$conductance, which is the predominant $\mathrm{Cl}^{-}$channel in this native tissue, as previously mentioned. The $\alpha$-toxin-induced deactivation of transepithelial $\mathrm{Cl}^{-}$conductance is reactivated by the addition of the CFTR agonist cAMP in the presence of a physiological concentration of ATP. b Summary of similar experiments as shown in a. Notice that $\alpha$-toxin-induced deactivation of $\mathrm{Cl}^{-}$ conductance is fully restored following application of cAMP + ATP in the cytoplasmic bath. (C) and (L) represent cytosolic bath and lumen, respectively. The data reflect mean \pm SE. * Significantly different from values before application of $\alpha$-toxin and after application of $\alpha$-toxin + cAMP: $P>0.001$ 
(0.1 mM), GTP- $\gamma-\mathrm{S}(0.1 \mathrm{mM})$, glutamate $(10 \mathrm{mM})$ or $\alpha$ ketoglutarate $(1 \mathrm{mM})$ was added to the cytoplasmic bath as needed. Endogenous phosphatases were inhibited by adding okadaic acid $\left(10^{-8} \mathrm{M}\right)$ to the cytoplasmic bath either before or after permeabilization as needed.

\section{Data Analysis}

The data are presented as the mean $\pm \mathrm{SE}$ (where $n$ is the number of ducts from at least four human subjects). Statistical significance was determined on the basis of Student's $t$-test for paired samples. $P<0.05$ was chosen to indicate a statistically significant difference. The data presented as electrophysiological traces are representative of experiments repeated at least three times.

\section{Results}

Effect of $\alpha$-Toxin Permeabilization

\section{Lumen to Cell $\mathrm{Cl}^{-}$Gradients}

Sweat ducts from non-CF subjects were initially perfused with $150 \mathrm{mM} \mathrm{NaCl}$ in the bath and $150 \mathrm{mM}$ $\mathrm{NaCl}+10^{-5} \mathrm{M}$ amiloride in the lumen. The bath perfusate was changed to $140 \mathrm{mM} \mathrm{KGlu}+5 \mathrm{mM}$ ATP before the application of $\alpha$-toxin in the bath. Before the application of $\alpha$-toxin, the sweat ducts were perifused with $140 \mathrm{mM} \mathrm{KGlu}+5 \mathrm{mM}$ ATP in the bath and perfused with $150 \mathrm{mM} \mathrm{NaCl}+$ amiloride (to block ENaCs). This maneuver caused a large depolarization of transepithelial potential that reflects predominant $\mathrm{Cl}^{-}$conductance in this tissue. During the initial phase of pore formation lasting for about 1-2 min, application of $\alpha$-toxin in the presence of $140 \mathrm{mM} \mathrm{KGlu}+5 \mathrm{mM}$ ATP in the basolateral bath compartment caused a small decline (or no change) in transepithelial conductance (pre- $\alpha$-toxin $G_{\mathrm{t}}=33 \pm 4 \mathrm{mS} /$ $\mathrm{cm}^{2}$ ) and potential (pre- $\alpha$-toxin $V_{\mathrm{Cl}}=45 \pm 5 \mathrm{~m} V$ ). Thereafter, a gradual decline occurred in both $G_{\mathrm{t}}$ (to the level of the nonspecific leak conductance $G_{\mathrm{x}}$, which is about $5 \pm 3 \mathrm{mS} / \mathrm{cm}^{2}$ ) and $V_{\mathrm{t}}$ (to the level of the junction potential, which is about $10 \pm 4 \mathrm{mV}, n=$ number of ducts from at least four human subjects) in $\sim 15 \mathrm{~min}$ after the application of $\alpha$-toxin (Fig. 1).

\section{No $\mathrm{Cl}^{-}$Gradient}

Application of $\alpha$-toxin in the absence of $\mathrm{Cl}^{-}$in the lumen and cytoplasmic bath had little effect on $V_{\mathrm{t}}(13 \pm 3 \mathrm{vs}$. $12 \pm 4 \mathrm{mV})$ and $G_{\mathrm{t}}\left(8 \pm 5\right.$ and $\left.4 \pm 6 \mathrm{mS} / \mathrm{cm}^{2}\right)$ before and after application of $\alpha$-toxin, respectively. The $V_{\mathrm{t}}$ and $G_{\mathrm{t}}$ in the absence of $\mathrm{Cl}^{-}$in the lumen and cytoplasmic bath reflect a nonspecific leak conductance because the only remaining apical $\mathrm{ENaC}$ conductance was blocked with amiloride in the lumen (Fig. 2).

\section{Sweat Ducts from $\triangle F 508 / \Delta F 508$ CF Subjects}

Sweat ducts from homozygous $(\Delta \mathrm{F} 508 / \Delta \mathrm{F} 508)$ or heterozygous $(\Delta \mathrm{F} 508 / \mathrm{R} 117 \mathrm{H}) \mathrm{CF}$ subjects were initially perfused with $150 \mathrm{mM} \mathrm{NaCl}$ in the bath and $150 \mathrm{mM}$ $\mathrm{NaCl}+$ amiloride in the lumen. Before the application of $\alpha$-toxin, the bath perfusate was changed from $150 \mathrm{mM}$ $\mathrm{NaCl}$ to $140 \mathrm{mM} \mathrm{KGlu}+5 \mathrm{mM}$ ATP (as described above for non-CF ducts). In contrast to the response of non-CF ducts, this maneuver caused very small depolarization of transepithelial potential in ducts from homozygous $\Delta \mathrm{F} 508 /$ $\Delta$ F508 CF patients (mostly reflects junction potential). Application of $\alpha$-toxin in the bath did not change the $V_{\mathrm{t}}$ or $G_{\mathrm{t}}$ in these ducts (Fig. 3a).

\section{Sweat Ducts from R117H/AF508 CF Subjects}

We noticed significant depolarization of transepithelial potential of heterozygous $(\Delta \mathrm{F} 508 / \mathrm{R} 117 \mathrm{H}) \mathrm{CF}$ ducts when bath $\mathrm{NaCl}$ was replaced with KGlu (Fig. 3b), although the magnitude of depolarization of these compound heterozygous CF ducts was relatively smaller compared to that of normal ducts (Figs. 1a, 3b). In contrast to the lack of electrical response of $\Delta \mathrm{F} 508$ homozygous $\mathrm{CF}$ ducts, the application of $\alpha$-toxin induced qualitatively similar electrical responses in heterozygous $(\Delta \mathrm{F} 508 / \mathrm{R} 117 \mathrm{H}$, i.e., gradual increase in transepithelial resistance corresponding with pore formation and loss of intracellular messengers) as observed in normal ducts (Figs. 1a, 3b).

\section{$\alpha$-Toxin-Induced Deactivation of CFTR}

\section{Effect of Okadaic Acid}

Pretreatment of sweat duct with okadaic acid $\left(10^{-8} \mathrm{M}\right)$ prevented deactivation of constitutively activated gCFTR following permeabilization of the basolateral membrane with $\alpha$-toxin. This is indicated by the fact that the $V_{\mathrm{Cl}}$ $(48 \pm 6 \mathrm{mV})$ and $\mathrm{gCl}\left(37 \pm 4 \mathrm{mS} / \mathrm{cm}^{2}\right)$ remained virtually unaffected by permeabilization so long as ATP was present in the cytoplasmic bath (Fig. 4).

\section{Effect of Glutamate}

$\alpha$-Toxin failed to deactivate gCFTR when applied in the presence of glutamate or its metabolite $\alpha$-ketoglutarate. The transepithelial potential and conductance remained high as long as glutamate or its metabolite $\alpha$-ketoglutarate remained in the cytoplasmic bath (Fig. 5a). In comparison, application 
A

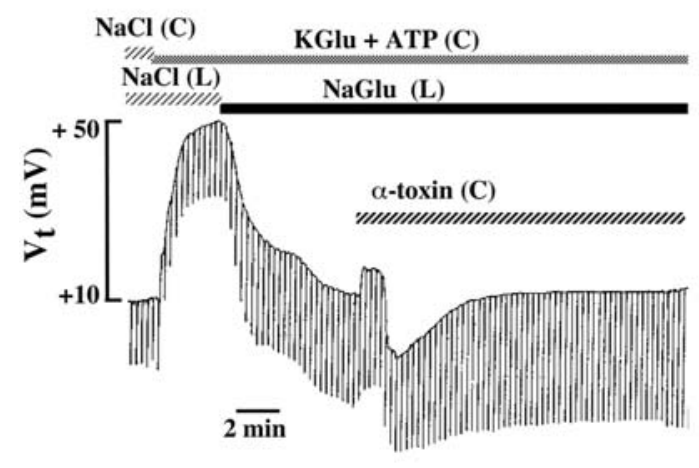

B

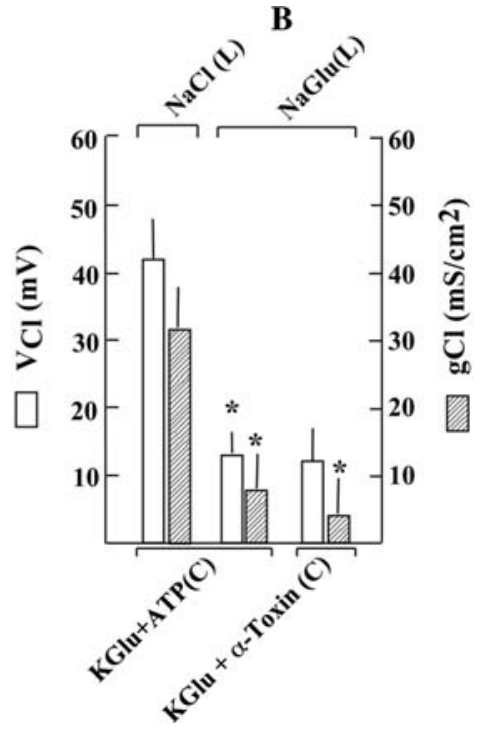

Fig. 2 Lack of effect of $\alpha$-toxin on the electrical properties of sweat duct in the absence of $\mathrm{Cl}^{-}$. a A representative electrical trace showing effect of $\alpha$-toxin in the complete absence of $\mathrm{Cl}^{-}$in the lumen and bath. In this experiment $\alpha$-toxin was applied after replacing the luminal $\mathrm{Cl}^{-}$with impermeant anion gluconate. Notice that replacing luminal $\mathrm{Cl}^{-}$with gluconate has a qualitatively similar effect as that induced by $\alpha$-toxin (i.e., loss of transepithelial electrical conductance and lumen positive electrical potential). These results further indicated that $\alpha$-toxin permeabilization inhibited apical CFTR $\mathrm{Cl}^{-}$ conductance. Activation of CFTR $\mathrm{Cl}^{-}$conductance was indicated by the changes in the amplitude of transepithelial current pulse indicated by downward voltage deflections and the lumen positive transepithelial $\mathrm{Cl}^{-}$diffusion potential induced by $150 \mathrm{mM} \mathrm{Cl}^{-}$in the lumen and $140 \mathrm{mM}$ impermeant anion gluconate (Glu) in the bath. b Summary of the results obtained from similar experiments as shown in a. Notice that transepithelial potential and conductance were significantly reduced in the absence of $\mathrm{Cl}^{-}$, which did not decrease any further following application of $\alpha$-toxin. (C) and (L) represent cytosolic bath and lumen, respectively. $*$ Significantly different from corresponding values in the presence of luminal $\mathrm{Cl}^{-}$before application of $\alpha$-toxin: $P>0.001$
A

$\Delta \mathbf{F 5 0 8 / \Delta F 5 0 8}$

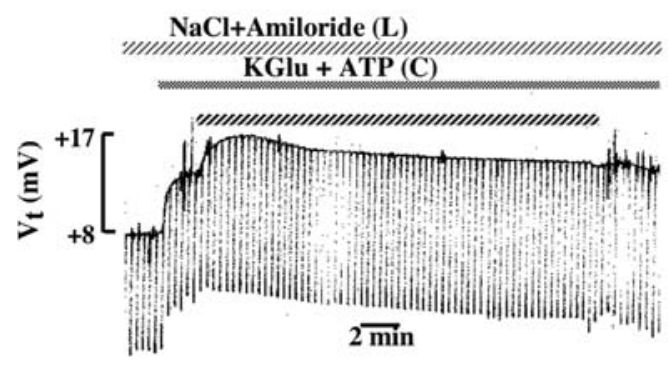

B

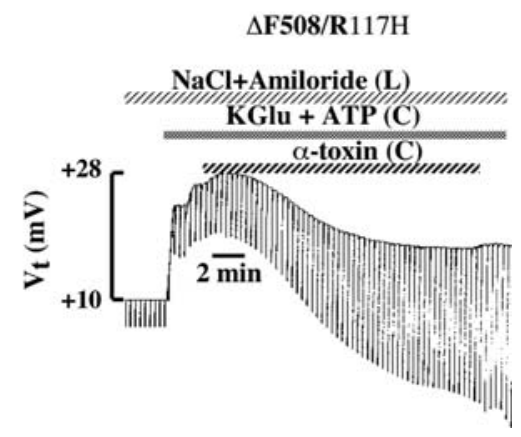

Fig. 3 a Effect of $\alpha$-toxin on the transepithelial potential and conductance in $\triangle \mathrm{F} 508$ homozygous $\mathrm{CF}$ ducts. In this experiment the lumen was perfused with $150 \mathrm{mM} \mathrm{NaCl}+$ amiloride and the bath was perifused with $140 \mathrm{mM} \mathrm{KGlu}+5 \mathrm{mM}$ ATP before $\alpha$-toxin application. Notice that there is a significantly smaller depolarization of transepithelial potential, reflecting absence of CFTR in the plasma membranes of this tissue. In contrast to the non-CF ducts, application of $\alpha$-toxin had little effect either on the transepithelial potential or on the conductance. b In contrast to the homozygous $\mathrm{CF}$ ducts,

of $\alpha$-toxin to the basolateral membrane completely deactivated gCFTR in the absence of glutamate as indicated by the reduction of transepithelial potential to the values representing the junction potentials $\left(V_{\mathrm{Cl}}=9 \pm 4 \mathrm{mV}\right)$ and heterozygous $\mathrm{CF}$ ducts with $\mathrm{R} 117 \mathrm{H} / \Delta \mathrm{F} 508$ mutations showed a small but consistent depolarization to the imposed $\mathrm{Cl}^{-}$gradient. In addition, application of $\alpha$-toxin resulted in a qualitatively similar response (abolition of transepithelial potential and conductance) as in normal ducts, but the magnitude of response was significantly smaller. These results are consistent with the fact that $\mathrm{R} 117 \mathrm{H} \mathrm{CF}$ mutation retains residual $\mathrm{Cl}^{-}$conductance. (C) and (L) represent cytosolic bath and lumen, respectively

leak conductance $\left(\mathrm{gCl}=5 \pm 3 \mathrm{mS} / \mathrm{cm}^{2}\right)$, respectively. Addition of glutamate alone (no ATP) restored gCFTR $\left(V_{\mathrm{Cl}}=62 \pm 8 \mathrm{~m} V\right.$ and $\left.\mathrm{gCl}=37 \pm 5 \mathrm{mS} / \mathrm{cm}^{2}, n=8\right)$ (Fig. 5b, c). 
A

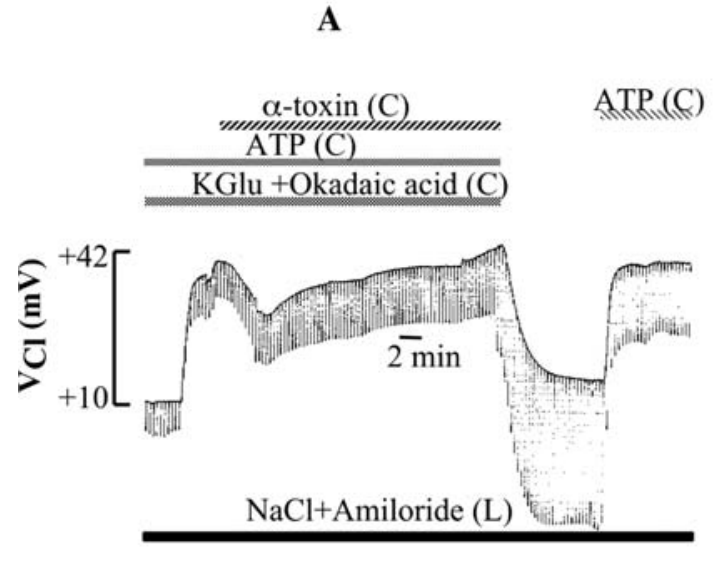

B

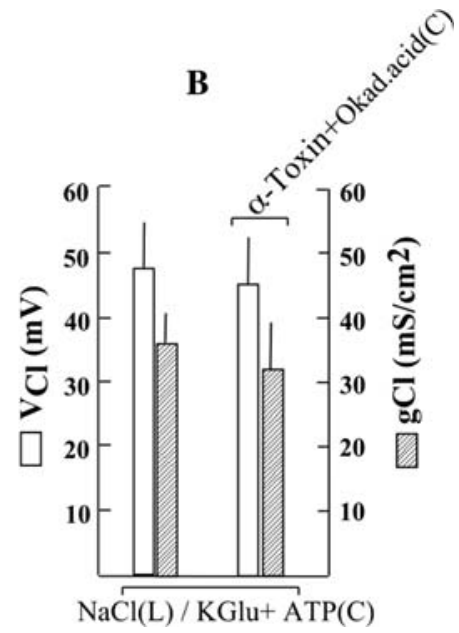

Fig. 4 Effect of okadaic acid on $\alpha$-toxin-induced deactivation of gCFTR. a A representative electrical trace showing the effect of PP2A inhibitor okadaic acid on the $\alpha$-toxin-induced deactivation of gCFTR. This experiment was designed to test the hypothesis that deactivation of CFTR $\mathrm{Cl}^{-}$conductance following $\alpha$-toxin permeabilization of the basolateral membrane is due to uninterrupted phosphatase dephosphorylation of CFTR in the absence of PKA phosphorylation activity (due to loss of cAMP through $\alpha$-toxin pores). Hence, inhibiting the endogenous phosphatase responsible for dephosphorylating CFTR should prevent deactivation of CFTR $\mathrm{Cl}^{-}$

\section{Effect of $G T P-\gamma-S$}

$\alpha$-Toxin-deactivated gCFTR could be reactivated via heterotrimeric $\mathrm{G}$ proteins in the apical membrane activated with $100 \mu \mathrm{M}$ GTP- $\gamma$-S and $5 \mathrm{mM}$ ATP in the cytoplasmic bath as shown by the fact that the post- $\alpha$-toxin-treated values of $V_{\mathrm{t}}(9.0 \pm 4 \mathrm{mV})$ and $G_{\mathrm{t}}\left(4 \pm 3 \mathrm{mS} / \mathrm{cm}^{2}\right)$ were restored to values comparable to those obtained after stimulating with cAMP + ATP or glutamate (Fig. 6a). That is, the $V_{\mathrm{Cl}}(50 \pm 5 \mathrm{mV})$ and $\mathrm{gCl}\left(39 \pm 8 \mathrm{mS} / \mathrm{cm}^{2}\right)$ after stimulating with $100 \mu \mathrm{M}$ GTP- $\gamma-\mathrm{S}$ in the presence of $5 \mathrm{mM}$ ATP were comparable to those observed in the presence of cAMP + ATP or glutamate (Fig. 6a).

\section{Okadaic Acid}

\section{Blocks Dephosphorylation of PKA-Activated CFTR}

We have previously shown that depletion of cytosolic $\mathrm{K}^{+}$ during transcellular $\mathrm{Na}^{+}$absorption causes progressive dephosphorylation deactivation of CFTR (Reddy and Quinton 2006). $\mathrm{K}^{+}$depletion (cytosolic $\mathrm{K}^{+}$substituted with $\mathrm{Na}^{+}$)-induced deactivation of CFTR was prevented by the application of okadaic acid $\left(10^{-8} \mathrm{M}\right)$, an inhibitor of PP2A. Figures $6 \mathrm{~b}$ and 7 show that inhibiting endogenous conductance following $\alpha$-toxin permeabilization. Notice that, consistent with this hypothesis, prior inhibition of phosphatase (most likely PP2A) with okadaic acid prevented CFTR deactivation after application of $\alpha$-toxin. CFTR remained activated as long as ATP was present in the cytoplasmic bath. b Summary of the data from similar experiments as shown in a. (C) and (L) represent cytosolic bath and lumen, respectively. The data indicate mean \pm SE. Notice that after treating the duct with okadaic acid, $\alpha$-toxin failed to deactivate CFTR$\mathrm{Cl}^{-}$conductance

okadaic acid-sensitive phosphatase prevents $\mathrm{K}^{+}$substitution-induced deactivation of cAMP-activated CFTR.

Does Not Block Dephosphorylation of G Protein-Activated CFTR

In contrast to the effect of okadaic acid on PKA-activated gCFTR, G protein-activated gCFTR remained sensitive to cytosolic changes in $\mathrm{K}^{+}$activity even in the presence of okadaic acid. That is, gCFTR was acutely inhibited by substituting cytoplasmic $\mathrm{K}^{+}$with $\mathrm{Na}^{+}$regardless of the presence or absence of okadaic acid and hence the PP2A activity (Figs. 6c, 7).

\section{Does Not Block Dephosphorylation of cGMP-Activated CFTR}

cGMP activated gCFTR in only about $45 \%$ of the ducts tested $(n=23)$. The magnitude of activation of gCFTR by cGMP in those responsive ducts varied $5-100 \%$ of the magnitude of cAMP-activated gCFTR (Fig. 8). In contrast to the effect of okadaic acid on PKA-activated gCFTR, the cGMP-activated gCFTR remained sensitive to cytosolic changes in $\mathrm{K}^{+}$activity even in the presence of okadaic acid. That is, gCFTR was acutely inhibited by substituting cytoplasmic $\mathrm{K}^{+}$with $\mathrm{Na}^{+}$regardless of the presence or absence of okadaic acid and hence the PP2A activity (Fig. 9). 

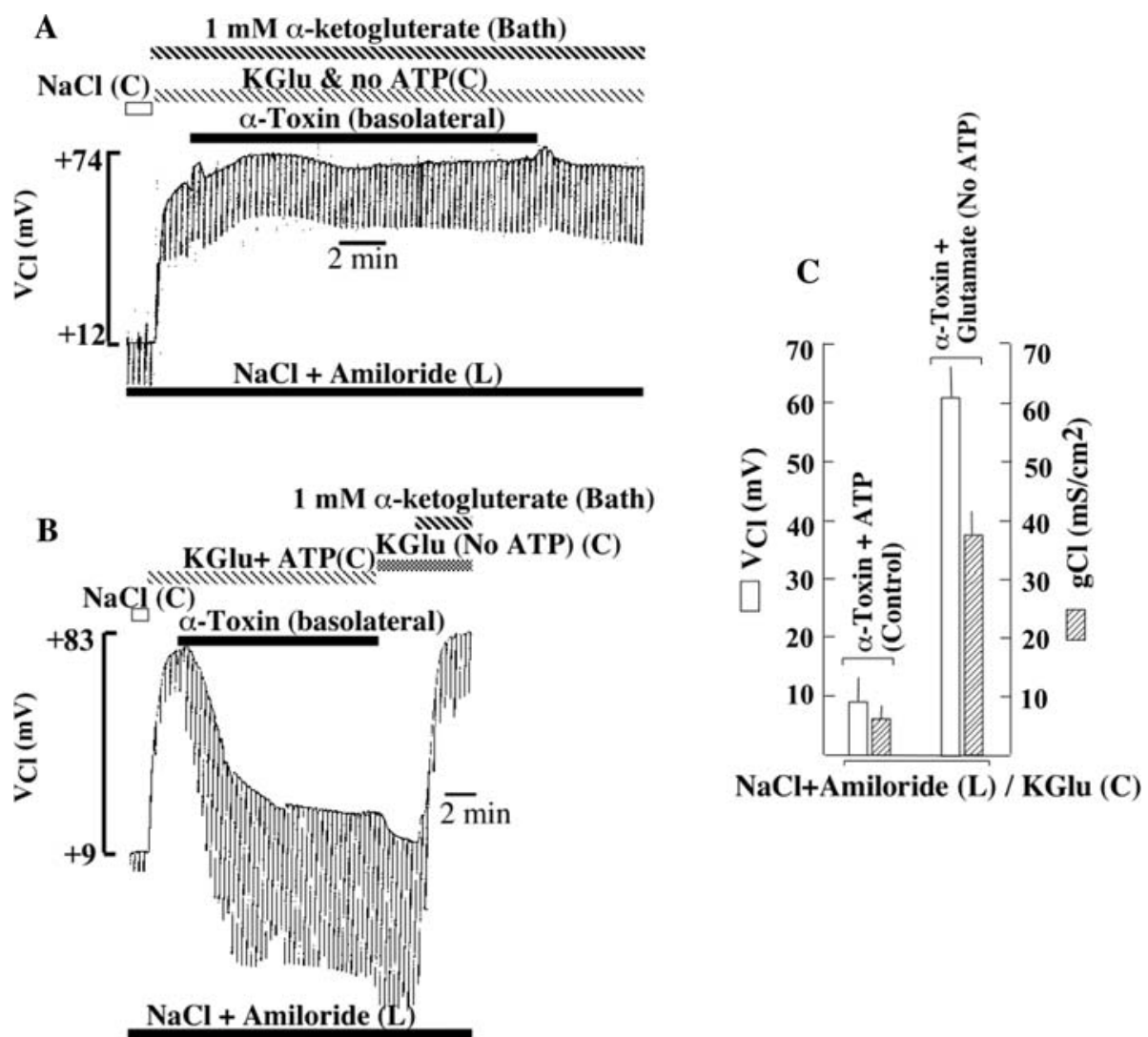

Fig. 5 Effect of glutamate on $\alpha$-toxin-induced deactivation of CFTR. a A representative electrical trace showing the effect of glutamate on $\alpha$-toxin-induced deactivation of gCFTR. Notice that the transepithelial conductance and $\mathrm{Cl}^{-}$diffusion potentials remained relatively unaffected by $\alpha$-toxin permeabilization in the presence of $1 \mathrm{mM} \alpha$ ketoglutarate in the cytosol. b In comparison to the lack of effect of $\alpha$ toxin as shown in a, $\alpha$-toxin permeabilization spontaneously decreased transepithelial $\mathrm{Cl}^{-}$conductance and diffusion potential in the absence of glutamate or its metabolite, which could be reversed immediately following application of $1 \mathrm{mM} \alpha$-ketoglutarate in the

\section{Discussion}

CFTR $\mathrm{Cl}^{-}$Conductance Is Constitutively Activated in the Human Sweat Duct

gCFTR appears fully activated in $\sim 75 \%$ of human sweat ducts under basal conditions (Fig. 8c). We have previously shown that no additional activation of gCFTR occurs upon exogenous stimulation by CFTR agonists such as the $\beta$ adrenergic agonist isoproterenol (IPR), permeable analogue of cAMP (CPT-cAMP) or activator of adenylate cyclase (forskolin), phosphodiesterase inhibitor (IBMX) and $\mathrm{PGE}_{2}$ (before or after inhibition of cyclooxygenase with indomethacin) (Reddy and Quinton 1992). Even in ducts that responded to CFTR agonists, the response was marginal so that the additional stimulus was $>15 \%$ of the maximal activated gCFTR, suggesting that $\sim 85 \%$ of the

cytosolic bath. c Summary of the results from similar experiments as shown in $\mathbf{a}$ and $\mathbf{b}$. Notice that the cytosolic glutamate or its metabolite caused activation of gCFTR that is almost similar in magnitude. The presence of glutamate prevents $\alpha$-toxin-induced deactivation of CFTR in the complete absence of ATP in the cytosol, indicating that glutamate activation of CFTR is independent of phosphorylation, as previously reported (Reddy and Quinton 2003). (C) and (L) represent cytosolic bath and lumen, respectively. The data represent mean $\pm \mathrm{SE}$

gCFTR was activated in $100 \%$ of the ducts tested for agonist response (Reddy and Quinton 1992). This phenomenon of constitutive activation of CFTR is not confined to sweat ducts alone but is also observed in other epithelial cells such as Calu-3 cells (Moon et al. 1997; Shen et al. 1994), pig trachea (unpublished personal observation) and small airways (Wang et al. 2005). The mechanisms of regulating CFTR can be broadly classified as those which involve phosphorylation and ATP and those that appear independent of phosphorylation and ATP. The first category includes multiple intracellular mediators such as cAMP (Berger et al. 1993; Cheng et al. 1991; Dulhanty and Riordan 1994), cGMP (French et al. 1995; Picciotto et al. 1992; Vaandrager et al. 1996, 1998), PKC (Berger et al. 1993; Jia et al. 1997), G proteins (Reddy and Quinton 2004; Reddy et al. 2001) and $\mathrm{Ca}^{2+}$ calmodulin kinase (Picciotto et al. 1992), not only in sweat ducts but also in 
A

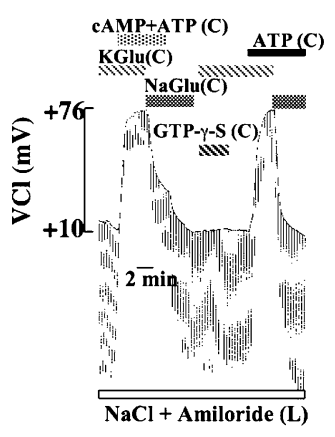

B

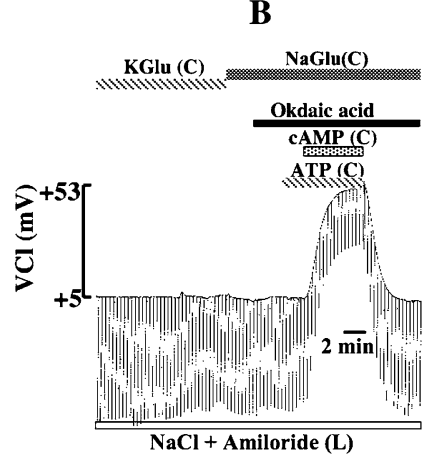

C

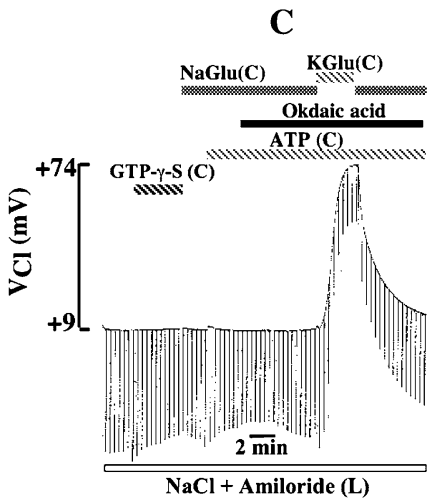

Fig. 6 Effect of cytosolic monovalent cations on phosphatase dephosphorylation of CFTR. a A representative electrical trace showing the effect of $\mathrm{K}^{+}$substitution with $\mathrm{Na}^{+}$on cAMP and $\mathrm{G}$ protein-activated CFTR. These experiments show that phosphorylation activation of $\mathrm{CFTR}-\mathrm{Cl}^{-}$conductance by cAMP and $\mathrm{G}$ proteins is sensitive to changes in cytosolic monovalent cation composition. That is, replacing cytosolic $\mathrm{K}^{+}$with $\mathrm{Na}^{+}$promptly deactivates gCFTR regardless of the mode of stimulation by cAMP or $\mathrm{G}$ proteins. $\mathrm{G}$ proteins are stimulated by GTP- $\gamma-\mathrm{S}$. b A representative experiment showing the effect of cytoplasmic $\mathrm{K}^{+}$substitution by $\mathrm{Na}^{+}$on cAMPactivated CFTR after application of PP2A inhibitor okadaic acid. Notice that, unlike in Fig. 5a, cAMP can activate CFTR even after complete $\mathrm{K}^{+}$substitution with $\mathrm{Na}^{+}$after inhibiting endogenous PP2A with okadaic acid. These results show that okadaic acid-sensitive phosphatase dephosphorylates cAMP-phosphorylated CFTR as previously reported. c A representative experiment showing the effect of cytoplasmic $\mathrm{K}^{+}$substitution by $\mathrm{Na}^{+}$on $\mathrm{G}$ protein-activated CFTR after application of the PP2A inhibitor okadaic acid. Notice that, unlike cAMP, G protein activation with GTP- $\gamma$-S failed to stimulate CFTR after complete $\mathrm{K}^{+}$substitution with $\mathrm{Na}^{+}$even in the presence of okadaic acid. These results show that G protein-activated CFTR is dephosphorylated by an okadaic acid-insensitive phosphatase. (C) and (L) represent cytosolic bath and lumen, respectively

first changing the deactivated state of CFTR from its constitutively activated state by depleting the putative cytosolic mediators that are suspected of being involved in the channel activation in vivo and then systematically examining which intracellular messenger might mediate the basal channel activity.

\section{How Does CFTR Change to a Deactivated State?}

In the absence of a clear understanding of which agonist is actually responsible for constitutively activating CFTR, it is difficult to predict the mechanisms involved in its deactivation. Early attempts to deactivate CFTR by inhibiting $\beta$-adrenergic receptors with the antagonist propranolol or the cyclooxygenase inhibitor indomethacin were unsuccessful (Quinton and Reddy 1991; Reddy and Quinton 1992). These results suggested either that (1) cAMP may not be the physiological agonist, (2) these maneuvers failed to significantly reduce intracellular cAMP levels due to weak phosphodiesterase activity, (3) weak endogenous phosphatase activity is responsible for dephosphorylating CFTR, (4) mechanisms other than cAMP-dependent phosphorylation may be involved such as cGMP or G protein-dependent kinase or (5) phosphorylation-independent mechanisms (such as glutamate-dependent activation) may be involved in keeping the CFTR channels constitutively activated. However, initial evidence that phosphorylation-dependent mechanisms may be responsible for the constitutive activation of CFTR in vivo is provided by the 
Fig. 8 Inconsistent cGMP regulation of CFTR. Unlike cAMP and G proteins, cGMP activation of CFTR is labile. The magnitude of activation of CFTR in sweat duct varied between the ducts and even within the same duct as a function of time. In some freshly isolated ducts the magnitude of cGMP activation of CFTR was comparable to that of cAMP (as shown in a), whereas in some other ducts the response is completely absent (as shown in b). cGMP stimulated gCFTR only in $\sim 45 \%$ of the ducts, while cAMP and $\mathrm{G}$ proteins stimulated CFTR in almost $100 \%$ of the sweat ducts (c). (C) and $(\mathrm{L})$ represent cytosolic bath and lumen, respectively
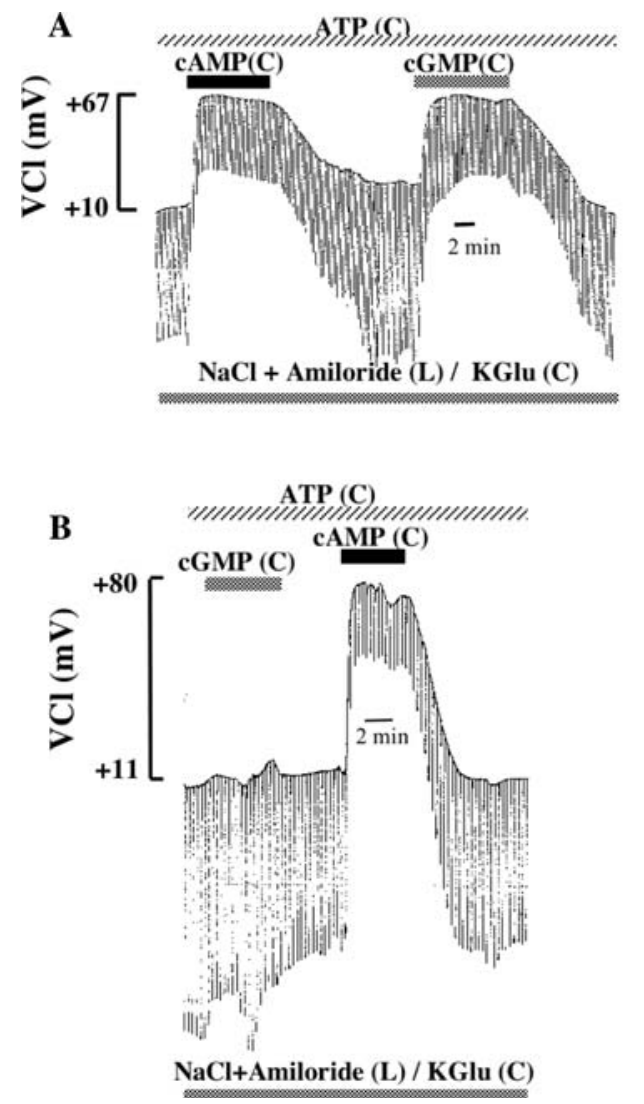

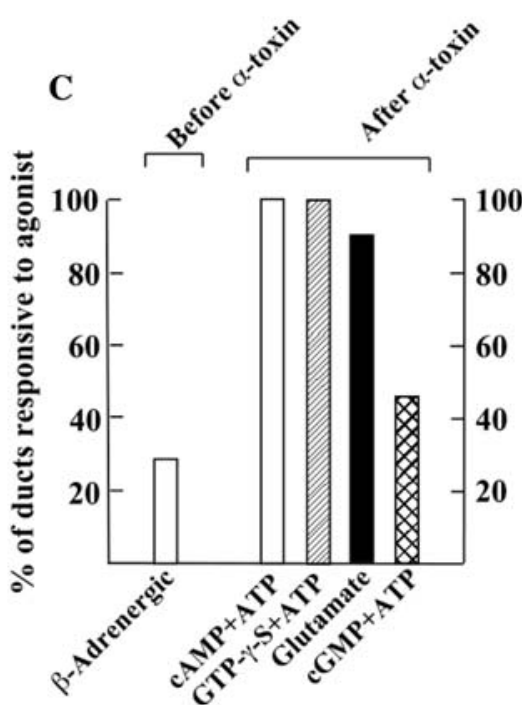

observation that the large transepithelial $\mathrm{Cl}^{-}$conductance of sweat duct is completely abolished following depletion of ATP by metabolic poisoning with CCCP and 2-DG (Quinton and Reddy 1992). ATP is an essential substrate in phosphorylation reactions besides being required for gating CFTR ion channels. Furthermore, glutamate stimulation of CFTR is independent of ATP. Therefore, the inhibitory effect of metabolic poisoning on gCFTR formed the basis of our hypothesis that endogenous kinase phosphorylation constitutively stimulates CFTR in sweat duct. We used $\alpha$ toxin-permeabilized sweat duct model to investigate this hypothesis based on the following rationale.

\section{$\alpha$-Toxin Permeabilization Causes Complete Deactivation of CFTR}

As previously reported, human sweat ducts predominantly express CFTR-Cl ${ }^{-}$conductance (Quinton 1986; Reddy and Quinton 1992) and $>80 \%$ of the transepithelial ion conductance is mediated by CFTR (Quinton 1986). After inhibiting the epithelial $\mathrm{Na}^{+}$conductance with amiloride, the apical membrane becomes almost exclusively $\mathrm{Cl}^{-}$selective, with minimal nonselective shunt conductance. The presence of $140 \mathrm{mM} \mathrm{KGlu}+5 \mathrm{mM}$ ATP (to partially mimic cytosolic conditions) in the bath and $150 \mathrm{mM} \mathrm{NaCl}+$ amiloride in the lumen causes a significant lumen positive $\mathrm{Cl}^{-}$diffusion potential (Fig. 1). Following permeabilization of the basolateral membrane with $\alpha$-toxin, the lumen positive potential gradually decreased to a value of about $+11 \mathrm{mV}$ (which is almost identical to the liquid junction potential) while simultaneously decreasing the transepithelial conductance to a value taken as a nonspecific shunt conductance (Fig. 1).

The following observations indicate that $\alpha$-toxin permeabilization of the basolateral membrane effectively deactivated gCFTR without causing significant damage to the apical membrane or the cytosolic macromolecular regulatory components such as kinases and phosphatases. First, substituting luminal $\mathrm{Cl}^{-}$with an impermeable anion gluconate (complete absence of $\mathrm{Cl}^{-}$in the basolateral side as well as luminal side) abolished lumen positive potential, as occurs following $\alpha$-toxin permeabilization (Fig. 2). Second, application of $\alpha$-toxin in the complete absence of $\mathrm{Cl}^{-}$did not significantly decrease transepithelial conductance, indicating that the decrease in electrical conductance in the presence of luminal $\mathrm{Cl}^{-}$is in fact due to decreased $\mathrm{Cl}^{-}$conductance. Third, application of a known CFTR agonist, cAMP, restored $\mathrm{Cl}^{-}$diffusion potential and conductance (Fig. 1), which was completely inhibited by the CFTR blocker CFTRInh172 (Reddy and Quinton 2002). Fourth, $\mathrm{Cl}^{-}$diffusion potential was either completely absent (in homozygous $\Delta$ F508 CF ducts that lack CFTR activity) (Quinton 1986) 
A

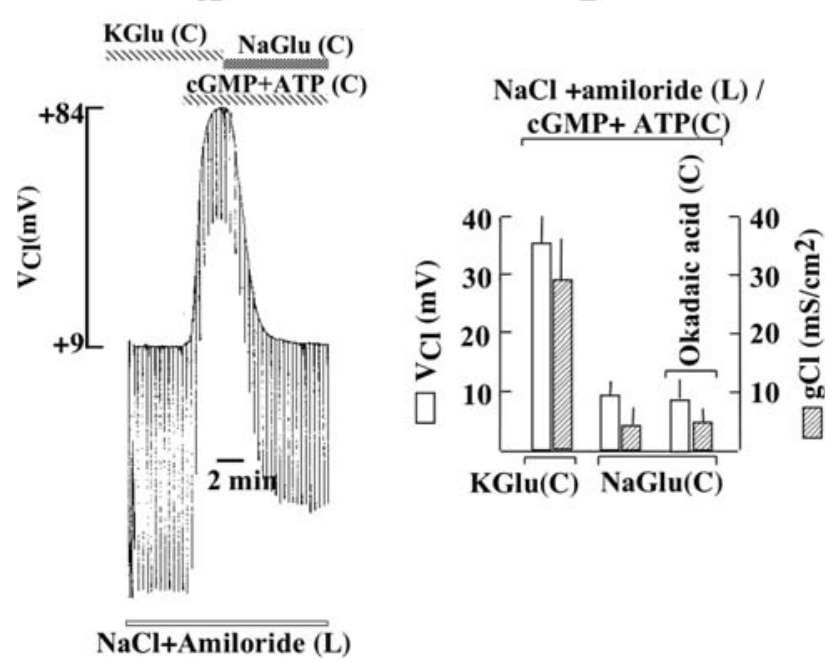

Fig. 9 Effect of cytosolic monovalent cations and okadaic acid on cGMP activation of gCFTR. a A representative electrical trace showing the effect of $\mathrm{K}^{+}$substitution with $\mathrm{Na}^{+}$on cGMP and activated CFTR. These experiments show that phosphorylation activation of $\mathrm{CFTR}_{-} \mathrm{Cl}^{-}$conductance by cGMP is sensitive to changes in cytosolic monovalent cation composition. That is, replacing cytosolic $\mathrm{K}^{+}$with $\mathrm{Na}^{+}$promptly deactivates cGMPactivated gCFTR. b The data show that okadaic acid has no effect on the inhibition of gCFTR following cytosolic $\mathrm{K}^{+}$substitution with $\mathrm{Na}^{+}$. These results indicate that, unlike PKA (cAMP)-phosphorylated CFTR, which is dephosphorylated by okadaic acid-sensitive phosphatase (Figs. 5, 6), PKG (cGMP)-phosphorylated CFTR is dephosphorylated by an okadaic acid-insensitive phosphatase, which is also sensitive to cytosolic changes in monovalent cations. (C) and (L) represent cytosolic bath and lumen, respectively

(Fig. 3a) or significantly smaller (in heterozygous R117H/ $\Delta$ F508 CF ducts that partially express CFTR activity) (Reddy and Quinton 2003) (Fig. 3b) compared to non-CF ducts (Fig. 1). Furthermore, permeabilization of the basolateral membrane with $\alpha$-toxin either had no effect in homozygous $\Delta$ F508 CF ducts (Fig. 3a) or had qualitatively similar but quantitatively smaller effects on transepithelial potential or conductance of $\mathrm{R} 117 \mathrm{H} / \Delta \mathrm{F} 508 \mathrm{CF}$ ducts, which is consistent with reduced gCFTR in these ducts. These results further support the notion that loss of $\mathrm{Cl}^{-}$diffusion potentials and conductance following $\alpha$-toxin permeabilization is in fact due to the loss of intracellular mediators that activate CFTR. We reasoned that a better understanding of the mechanism(s) underlying $\alpha$-toxin-induced deactivation of gCFTR may provide insights to the physiological mechanism responsible for constitutive activation of CFTR in vivo.

Endogenous Phosphorylation Is Responsible for Constitutive Activation of CFTR

After establishing the fact that $\alpha$-toxin permeabilization causes CFTR deactivation due to loss of intracellular messengers, we sought to determine whether kinase phosphorylation or cytosolic glutamate metabolites keep CFTR constitutively activated. We reasoned that if kinase phosphorylation is responsible for deactivation of CFTR following $\alpha$-toxin permeabilization, preventing dephosphorylation of CFTR by inhibiting endogenous phosphatase activity before application of $\alpha$-toxin should prevent deactivation of the channels following $\alpha$-toxin permeabilization. We used okadaic acid to inhibit the phosphatase activity because it was shown to prevent dephosphorylation deactivation of cAMP-activated CFTR in the human sweat duct (Reddy and Quinton 1996) and in patch-clamp studies using heterologous expression systems in which okadaic acid-sensitive PP2A was shown to prevent dephosphorylation of the channel (Berger et al. 1993). As shown in Fig. 4, when endogenous phosphatase activity was inhibited by okadaic acid, subsequent permeabilization of basolateral membrane with $\alpha$-toxin had little effect on the transepithelial $\mathrm{Cl}^{-}$diffusion potential and conductance. gCFTR remained activated as long as ATP was present in the cytoplasmic bath. If a phosphorylationindependent, glutamate-dependent mechanism was involved in constitutive activation of CFTR, we should have seen spontaneous deactivation of CFTR following $\alpha$ toxin application even after inhibiting the phosphatase activity because permeabilization also allows glutamate to diffuse in and out of the cytosol through $\alpha$-toxin pores, as shown in Fig. 5. These results indicated that constitutive activation of CFTR is most likely due to persistent phosphorylation of CFTR by endogenous kinases whose activity far exceeds that of endogenous okadaic acidsensitive phosphatase.

Which Kinase Is Responsible for Constitutive Activation In Vivo?

We have previously shown that CFTR can be activated by PKA, PKG and heterotrimeric G protein-dependent kinase (Reddy et al. 1999). Therefore, the question arises as to which one of these kinases is responsible for constitutively activating CFTR. We now know that inhibition of an endogenous okadaic acid-sensitive PP2A prevents deactivation of CFTR following $\alpha$-toxin permeabilization. Therefore, we investigated whether PP2A specifically deactivates either PKA, PKG or G protein-phosphorylated CFTR with the following rationale. If okadaic acid-sensitive phosphatase acts only on PKA but not PKG and G protein-dependent kinase-phosphorylated CFTR, we can conclude that PKA is most likely to be the kinase (and not PKG or G proteins) that phosphorylates CFTR to keep it constitutively activated in vivo. The following evidence appears to be consistent with this notion. 
G Protein-Dependent Kinase Is Not Responsible for Constitutive Activation of CFTR

We have previously shown that apical heterotrimeric $G$ proteins activate a cAMP-independent kinase that causes phosphorylation activation of CFTR in the presence of ATP in the human sweat duct (Reddy and Quinton 2001; Reddy et al. 2001). G protein control of CFTR has been demonstrated in airway epithelial cells (Schwiebert et al. 1992). Stretch-induced stimulation of heterotrimeric G proteins is well documented (Gudi et al. 1996). Since luminal fluid flow during physiological sweating or under microperfusion conditions is expected to stretch the apical membrane, it seems logical that any activation of $G$ proteins during luminal perfusion could stimulate CFTR by $G$ protein-dependent kinase phosphorylation. Therefore, we examined if the dephosphorylation deactivation of $\mathrm{G}$ protein-activated CFTR is sensitive to okadaic acid with the following rationale. If constitutive activation of CFTR is due to activation of heterotrimeric $G$ proteins, then the endogenous phosphatase responsible for dephosphorylating and deactivating $G$ protein-activated CFTR must be inhibited by okadaic acid. Otherwise, deactivation of CFTR following $\alpha$-toxin-induced pore formation cannot be prevented by okadaic acid. We investigated this question by exploiting the fact that okadaic acid-sensitive endogenous phosphatases responsible for dephosphorylating CFTR are inhibited by cytosolic $\mathrm{K}^{+}$(Reddy and Quinton 2006). Substituting cytosolic $\mathrm{K}^{+}$with $\mathrm{Na}^{+}$caused significant activation of okadaic acid-sensitive phosphatase activity, resulting in the dephosphorylation deactivation of CFTR (Reddy and Quinton 2006). Our results (Figs. 6, 7) show that CFTR activated by both cAMP and G proteins could be deactivated by substituting $\mathrm{K}^{+}$in the cytoplasmic bath with $\mathrm{Na}^{+}$. However, inhibiting the endogenous phosphatase with okadaic acid only prevented $\mathrm{K}^{+}$depletion-induced deactivation of cAMP-, but not G protein-, activated CFTR (Fig. 6, 7). These results indicate that two distinctly different endogenous phosphatases dephosphorylate CFTR activated by cAMP and the G proteins. That is, cAMPdependent protein kinase and the $G$ protein-dependent kinase must be phosphorylating different sites on CFTR that are targeted by two different phosphatases, only one of which is sensitive to okadaic acid. In other words, these results indicate that (1) different phosphatases are responsible for dephosphorylating CFTR that had been phosphorylated by cAMP-dependent kinase (PKA) and G protein-activated kinase and (2) okadaic acid-sensitive phosphatase is only responsible for dephosphorylating PKA-, but not G protein-, phosphorylated CFTR.
cGMP Is Also Not Likely to Support Constitutive Activation

Even though gCFTR can be activated by cGMP after $\alpha$ toxin permeabilization, either a majority of sweat ducts $(55 \%)$ did not respond at all or, if they responded, the magnitude of activation of gCFTR by this agonist was significantly smaller than that of cAMP or G protein agonist GTP- $\gamma-S$ (Fig. 8). In fact, gCFTR could be stimulated by cGMP only in $\sim 45 \%$ of the ducts after $\alpha$-toxin permeabilization vs. $100 \%$ of the ducts responding to stimulation by cAMP and G protein activation by GTP- $\gamma-S$ after permeabilization (Fig. 8). These results suggest that PKG activity is either very weak or absent in a majority of sweat ducts for reasons that we do not understand at this time. In contrast, gCFTR is fully activated under basal unstimulated conditions in $\sim 70 \%$ of intact ducts. It is therefore unlikely that the cAMP regulatory pathway, which is only partially operational in only $\sim 45 \%$ of the ducts, could be responsible for constitutive activation of CFTR (mostly if not fully) in almost $100 \%$ of the ducts. Hence, loss of cGMP cannot be responsible for consistent deactivation of CFTR following $\alpha$-toxin permeabilization. Preliminary results also indicated that even in those ducts in which cGMP could stimulate CFTR as effectively as cAMP (Figs. 8, 9), application of okadaic acid only prevented dephosphorylation of cAMP-, but not cGMP-, stimulated CFTR (Fig. 9). These results indicate that (1) different phosphatases are responsible for dephosphorylating PKA- and PKG-phosphorylated CFTR and (2) okadaic acid-sensitive phosphatase is only responsible for dephosphorylating PKA-, but not PKG-, phosphorylated CFTR.

PKA Phosphorylation Seems to Be Responsible for Basal CFTR Activity In Vivo

It is now evident that neither G protein- nor PKG-phosphorylated CFTR can be dephosphorylated by okadaic acid-sensitive PP2A. Therefore, inhibiting this phosphatase with okadaic acid would have no effect on the deactivation of CFTR following $\alpha$-toxin permeabilization, had either of these kinases been responsible for constitutive activation of CFTR. Furthermore, since glutamate activation of CFTR is independent of ATP and phosphorylation (Reddy and Quinton 2003), okadaic acid would not have had any effect on the $\alpha$-toxin-induced deactivation of CFTR, had this agonist been responsible for the constitutive activation of CFTR in vivo. Therefore, it seems most likely that PKA phosphorylation controlled by $\mathrm{PP} 2 \mathrm{~A}$ is responsible for basal endogenous activation of CFTR in this tissue and possibly in most other epithelial cells in which PKA 
appears to be the predominant regulator of CFTR activity (Gadsby and Nairn 1999; Schwiebert et al. 1999).

\section{Why Is CFTR Under Multiple Regulatory Controls?}

The observation that PKA phosphorylation is responsible for basal CFTR activity in the human sweat duct raises the question of whether this is true in other tissues that express CFTR. cAMP is the predominant activator of CFTR $\mathrm{Cl}^{-}$ conductance in most epithelial cells (Gadsby and Nairn 1999). $\beta$-Adrenergic stimulation appears to act via the $G$ protein-coupled adenyl cyclase/cAMP cascade to stimulate CFTR-mediated secretions in a number of exocrine glands including sweat glands, airways and salivary glands (Gadsby and Nairn 1999; Quinton 1999). Therefore, even though CFTR can be activated by several agonists, cAMP/ PKA-dependent activation of CFTR may be the predominant intracellular mechanism responsible for maintaining basal CFTR activity in most epithelial cells. Accepting this notion leads to the question of why CFTR is subject to regulation by so many different mechanisms in the same tissue, as observed here. Part of the answer may lie in our early observation that cAMP fails to fully activate gCFTR in sweat ducts from some individuals (Reddy et al. 2008). This may be due to strong endogenous activity of okadaic acid-sensitive phosphatase, responsible for deactivating PKA-phosphorylated CFTR or relatively weak PKA activity resulting in minimal activation of CFTR channels (Reddy et al. 2008). Cytosolic alkalinization (pH 8.5) was shown to inhibit this phosphatase and stimulate PKA while significantly enhancing cAMP-stimulated gCFTR (Reddy et al. 2008). Even though the mechanism underlying such unusually small cAMP activation of CFTR is unknown at this time, back-up mechanisms of stimulating CFTR by alternative pathways such as the one mediated by G proteins may provide critical protection of a significant physiological function of conserving salt during exercise. This is particularly significant in subjects with unusually large okadaic acid-sensitive PP2A or weak PKA activity. Furthermore, the mechanisms involved in the $G$ protein regulation of CFTR may be tissue-specific. Unlike in the sweat ducts, where activating $G$ proteins causes increased CFTR channel function, heterotrimeric $\mathrm{G}$ proteins coupled to adenosine receptors may downregulate CFTR in the airways (Schwiebert et al. 1992).

The physiological significance of cGMP regulation is intriguing because this agonist activates CFTR in $<50 \%$ of the ducts. This observation suggests that cGMP regulation is triggered by specific physiological situations that are not defined at this time. However, preliminary data indicated that cGMP along with cytosolic glutamate seem to potentiate $\mathrm{HCO}_{3}{ }^{-}$conductance through CFTR (Reddy and Quinton 2003, 2005a, 2008). Since cGMP appears to be the predominant mechanism of regulating CFTR in the intestinal epithelium, it seems possible that this specific regulatory mechanisms may be associated with a tissue-specific function such as bicarbonate secretion to neutralize acid (due to bacterial activity) or facilitate mucous secretion in the gut, which needs further investigation.

Likewise, the exact physiological role of glutamate in regulating CFTR anion channel function is unclear. However, it is an important intracellular osmolyte. Preliminary evidence suggests that the glutamate regulatory mechanism appears to be sensitive to changes in both luminal and cytosolic $\mathrm{Na}^{+}$concentration. Therefore, this regulatory mechanism may help in the control of salt transport activity at the apical membrane (Reddy and Quinton 2005b). In addition, in the presence of ATP, glutamate seems to play a significant role in increasing the $\mathrm{HCO}_{3}{ }^{-}$selectivity of CFTR, which could have important implications for regulating the $\mathrm{pH}$ of cytosolic as well as exocrine secretory fluids (Reddy and Quinton 2003).

\section{Implications for Electrolyte Transport in CF}

Even though it is well known that CFTR can be phosphorylation-activated by different kinases, it was unclear whether these kinases phosphorylate common sites or different kinase-specific sites. The observation that okadaic acid-sensitive phosphatase only dephosphorylates PKA but not the G protein- and cGMP-dependent kinase-phosphorylated CFTR indicates that different endogenous phosphatases specifically dephosphorylate distinct PKA, G protein and cGMP-phosphorylated sites. Pharmacological efforts to manipulate mutant CFTR activity in CF cells may have to take into account this fact. That is, one must also consider whether a given CF mutation affects just PKA and not other (G protein and cGMP) mechanisms as well so that they can be exploited as alternative modes of activating different mutant forms of CFTR. These results also indicate that the phosphorylation-activated CFTR is deactivated by depletion of cytosolic $\mathrm{K}^{+}$regardless of the kinase (i.e., $\mathrm{G}$ protein-activated kinase and $\mathrm{PKG}$ ) involved (Figs. 6, 9). Since cytosolic $\mathrm{K}^{+}$activity appears to be a function of transepithelial salt transport (Reddy and Quinton 2006), therapeutic strategies aimed at manipulating salt transport to treat electrolyte transport disorder in CF may have to consider potential changes in cytosolic monovalent cation composition during chronic pharmacological treatments. For example, attempts to decrease $\mathrm{Na}^{+}$ absorption by chronic amiloride treatment might increase cytosolic $\mathrm{K}^{+}$activity (Reddy and Quinton 1991, 2006), and likewise pharmacological intervention to increase basolateral $\mathrm{K}^{+}$conductance to enhance electrical driving force for $\mathrm{Cl}^{-}$secretion (Schultz et al. 1999) may decrease cytosolic $\mathrm{K}^{+}$concentration (Sato et al. 1993; Suzuki et al. 1991; 
Takemura et al. 1991), with potential implications for endogenous phosphorylation processes involving not only CFTR but also other vital physiological functions in the affected epithelial cells.

\section{Conclusions}

The CFTR $\mathrm{Cl}^{-}$conductance in the native human sweat duct is constitutively activated by PKA phosphorylation. Different phosphatases appear to dephosphorylate PKA-, G protein- and PKG-activated CFTR. Okadaic acid-sensitive PP2A can only deactivate PKA but not G protein- and cGMP-activated CFTR. PKA phosphorylation is sensitive to cytosolic changes in monovalent cation composition regardless of the kinase (PKA, PKG and G protein-activated kinase) involved. Therapeutic strategies aimed at curing CF must take into account the fact that multiple independent regulatory controls may exist within the same tissue that can be exploited to activate different mutant forms of CFTR.

Acknowledgements The authors are grateful to Mr. Kirk Taylor for expert technical assistance and the numerous subjects who volunteered for skin biopsy. This work was funded by NIH-RO1 DE14352, NIH-RO1HL08042, NIH 1R01 HL 096732-01, R01 DK 55835-09 (NIDDK 2010-1223), USPHSR01 DK 51889, the Nancy Olmsted Trust and the Cystic Fibrosis Foundation.

Open Access This article is distributed under the terms of the Creative Commons Attribution Noncommercial License which permits any noncommercial use, distribution, and reproduction in any medium, provided the original author(s) and source are credited.

\section{References}

Berger HA, Travis SM, Welsh MJ (1993) Regulation of the cystic fibrosis transmembrane conductance regulator $\mathrm{Cl}^{-}$channel by specific protein kinases and protein phosphatases. J Biol Chem 268:2037-2047

Cheng SH, Rich DP, Marshall J, Gregory RJ, Welsh MJ, Smith AE (1991) Phosphorylation of the R domain by cAMP-dependent protein kinase regulates the CFTR chloride channel. Cell 66:1027-1036

Dulhanty AM, Riordan JR (1994) Phosphorylation by cAMPdependent protein kinase causes a conformational change in the $\mathrm{R}$ domain of the cystic fibrosis transmembrane conductance regulator. Biochemistry 33:4072-4079

Fischer H, Illek B, Machen TE (1998) Regulation of CFTR by protein phosphatase 2B and protein kinase C. Pfluegers Arch 436:175-181

French PJ, Bijman J, Edixhoven M, Vaandrager AB, Scholte BJ, Lohmann SM, Nairn AC, De Jonge HR (1995) Isotype-specific activation of cystic fibrosis transmembrane conductance regulator-chloride channels by cGMP-dependent protein kinase II. J Biol Chem 270:26626-26631

Gadsby DC, Nairn AC (1999) Control of CFTR channel gating by phosphorylation and nucleotide hydrolysis. Physiol Rev 79:S77S107
Greger R (1981) Cation selectivity of the isolated perfused cortical thick ascending limb of Henle's loop of rabbit kidney. Pfluegers Arch 390:30-37

Gudi SR, Clark CB, Frangos JA (1996) Fluid flow rapidly activates G proteins in human endothelial cells. Involvement of $\mathrm{G}$ proteins in mechanochemical signal transduction. Circ Res 79:834-839

Helman SI, Grantham JJ, Burg MB (1971) Effect of vasopressin on electrical resistance of renal cortical collecting tubules. Am J Physiol 220:1825-1832

Jia Y, Mathews CJ, Hanrahan JW (1997) Phosphorylation by protein kinase $\mathrm{C}$ is required for acute activation of cystic fibrosis transmembrane conductance regulator by protein kinase A. J Biol Chem 272:4978-4984

Luo J, Pato MD, Riordan JR, Hanrahan JW (1998) Differential regulation of single CFTR channels by PP2C, PP2A, and other phosphatases. Am J Physiol 274:C1397-C1410

Moon S, Singh M, Krouse ME, Wine JJ (1997) Calcium-stimulated $\mathrm{Cl}^{-}$secretion in Calu-3 human airway cells requires CFTR. Am J Physiol 273:L1208-L1219

Picciotto MR, Cohn JA, Bertuzzi G, Greengard P, Nairn AC (1992) Phosphorylation of the cystic fibrosis transmembrane conductance regulator. J Biol Chem 267:12742-12752

Quinton PM (1986) Missing Cl conductance in cystic fibrosis. Am J Physiol 251:C649-C652

Quinton PM (1999) Physiological basis of cystic fibrosis: a historical perspective. Physiol Rev 79:S3-S22

Quinton PM, Reddy MM (1991) Regulation of absorption in the human sweat duct. Adv Exp Med Biol 290:159-170

Quinton PM, Reddy MM (1992) Control of CFTR chloride conductance by ATP levels through non-hydrolytic binding. Nature 360:79-81

Quinton PM, Reddy MM (1994) Regulation of absorption by phosphorylation of CFTR. Jpn J Physiol 44(suppl 2):S207-S213

Reddy MM, Quinton PM (1991) Intracellular potassium activity and the role of potassium in transepithelial salt transport in the human reabsorptive sweat duct. J Membr Biol 119:199-210

Reddy MM, Quinton PM (1992) cAMP activation of CF-affected $\mathrm{Cl}^{-}$ conductance in both cell membranes of an absorptive epithelium. J Membr Biol 130:49-62

Reddy MM, Quinton PM (1994) Rapid regulation of electrolyte absorption in sweat duct. J Membr Biol 140:57-67

Reddy MM, Quinton PM (1996) Deactivation of CFTR-Cl conductance by endogenous phosphatases in the native sweat duct. Am J Physiol 270:C474-C480

Reddy MM, Quinton PM (2001) cAMP-independent phosphorylation activation of CFTR by $\mathrm{G}$ proteins in native human sweat duct. Am J Physiol 280:C604-C613

Reddy MM, Quinton PM (2002) Effect of anion transport blockers on CFTR in the human sweat duct. J Membr Biol 189:15-25

Reddy MM, Quinton PM (2003) Control of dynamic CFTR selectivity by glutamate and ATP in epithelial cells. Nature 423:756-760

Reddy MM, Quinton PM (2004) Distinctly different phosphatases deactivate PKA and G protein-activated CFTR in sweat duct. Pediatr Pulmonol Suppl 26:196

Reddy MM, Quinton PM (2005a) Physiological regulation of CFTR $\mathrm{Cl}^{-}$conductance by cGMP in sweat duct. FASEB J 19, abstract 672.48

Reddy MM, Quinton PM (2005b) Potassium sensitive phosphatases deactivate phosphorylation but not glutamate activated CFTR. Pediatr Pulmonol Suppl 28:207

Reddy MM, Quinton PM (2006) Cytosolic potassium controls CFTR deactivation in human sweat duct. Am J Physiol 291:C122-C129

Reddy MM, Quinton PM (2008) Synergistic regulation of CFTRbicarbonate conductance by protein kinases and glutamate in the human sweat duct. IUPS abstracts. FASEB J 22, abstract 934.5 
Reddy MM, Kopito RR, Quinton PM (2008) Cytosolic pH regulates $\mathrm{GCl}$ through control of phosphorylation states of CFTR. Am J Physiol 275(Cell Physiol 44):C1040-C1047

Reddy MM, Light MJ, Quinton PM (1999) Activation of the epithelial $\mathrm{Na}^{+}$channel $(\mathrm{ENaC})$ requires CFTR $\mathrm{Cl}^{-}$channel function. Nature 402:301-304

Reddy MM, Sun D, Quinton PM (2001) Apical heterotrimeric G proteins activate CFTR in the native sweat duct. J Membr Biol 179:51-61

Sato K, Ohtsuyama M, Sato F (1993) Whole cell K and Cl currents in dissociated eccrine secretory coil cells during stimulation. J Membr Biol 134:93-106

Schultz BD, Singh AK, Devor DC, Bridges RJ (1999) Pharmacology of CFTR chloride channel activity. Physiol Rev 79:S109-S144

Schwiebert EM, Kizer N, Gruenert DC, Stanton BA (1992) GTPbinding proteins inhibit cAMP activation of chloride channels in cystic fibrosis airway epithelial cells. Proc Natl Acad Sci USA 89:10623-10627

Schwiebert EM, Benos DJ, Egan ME, Stutts MJ, Guggino WB (1999) CFTR is a conductance regulator as well as a chloride channel. Physiol Rev 79:S145-S166
Shen BQ, Finkbeiner WE, Wine JJ, Mrsny RJ, Widdicombe JH (1994) Calu-3: a human airway epithelial cell line that shows cAMP-dependent $\mathrm{Cl}^{-}$secretion. Am J Physiol 266:L493-L501

Suzuki Y, Ohtsuyama M, Samman G, Sata F, Sato K (1991) Ionic basis of methacholine-induced shrinkage of dissociated eccrine clear cells. J Membr Biol 123:33-41

Takemura T, Sato F, Saga K, Suzuki Y, Sato K (1991) Intracellular ion concentrations and cell volume during cholinergic stimulation of eccrine secretory coil cells. J Membr Biol 119:211-219

Vaandrager AB, Ehlert EM, Jarchau T, Lohmann SM, de Jonge HR (1996) N-terminal myristoylation is required for membrane localization of cGMP-dependent protein kinase type II. J Biol Chem 271:7025-7029

Vaandrager AB, Smolenski A, Tilly BC, Houtsmuller AB, Ehlert EM, Bot AG, Edixhoven M, Boomaars WE, Lohmann SM, de Jonge HR (1998) Membrane targeting of cGMP-dependent protein kinase is required for cystic fibrosis transmembrane conductance regulator $\mathrm{Cl}^{-}$channel activation. Proc Natl Acad Sci USA 95:1466-1471

Wang X, Lytle C, Quinton PM (2005) Predominant constitutive CFTR conductance in small airways. Respir Res 6:7 